\title{
Investigating the Relationship between Educational Stress and Emotional Self-Efficacy
}

\author{
Nihan Arslan \\ Faculty of Education, Fatih Sultan Mehmet Vakıf University, Turkey
}

Copyright $\mathrm{C} 2017$ by authors, all rights reserved. Authors agree that this article remains permanently open access under the terms of the Creative Commons Attribution License 4.0 International License

\begin{abstract}
The objective of study is the underlying to relationship between emotional self-efficacy and educational stress with a structural equation model. The research was conducted on 232 secondary school students. Emotional self-efficacy scale and educational stress scale were used in the study. It was found that there was a negative correlation between emotional self-efficacy and educational stress. Findings obtained from the structural equation model; educational stress were negatively predicted by emotional self-efficacy. The fit index obtained from the structural equation model show that the model fits well. Findings are discussed depending on the literature.
\end{abstract}

Keywords Emotional Self-efficacy, Educational Stress, Structural Equation Modeling

\section{Introduction}

\subsection{Educational Stress}

Stress is an over- arousal situation that emerges in physical and psychological aspects, as a result of evaluating internal or external factors as dangerous or harmful [27]. Stress may be derived from traumatic life events (like parental loss), continuous troubles (like economic troubles), and problems in daily life (like argument with friends) [20].The strength and effect of stress resource can change from person to person and case to case. Researchers carried out with people and animals show that long term stress causes cognitive, emotional and behavioral problems [49]. In addition to stress resources, teachers and school also affect stress situation seriously. According to Jones [23], stress level of children and adolescents depends on time, which students spend at schools and academic activities. Educational stress is also called as academic stress and defined as discomfort and anxiety that is caused by different troubles of academic learning experience [41]. Verma and Gupta [43] stated that academic stress is a disappointment about academic failure, and a mental distress that is characterized by fear of being unsuccessful. Academic stress causes substance use, unhealthy nutrition, and depression; and affects self-care skills negatively [45, 46]. According to the study of American Health Association that was carried out with 97.357 students in 2006, 32 percent of students consider educational stress as a reason for low grades and dropout [44]. High expectations, information overload, academic pressure, unrealistic ambitions, limited opportunities and high competition are the most common causes of academic stress [33]. Educational stress decreases performance, poses a threat to students' well-being, and causes mental and physical health problems [31]. Lack of self-confidence, somatization disorders, suicide ideation, negative sense of self are the situations that are derived from educational stress $[21,2]$. Perceived stress differs from according to variables such as gender, cultural differences, and socioeconomic status. Researchers indicate that male students experience less educational stress than female students $[24,10,13,48$, 50]. This finding typically can be because female students pay more attention to school performance and they are more worried about academic failure [24]. Students, who have a disadvantaged history as compared to their peers, experience more educational stress [28].

\subsection{Emotional Self-efficacy}

Self-efficacy is one's belief in one's own ability to complete tasks [5], who claimed that self-efficacy plays a bridge role between information and action, indicated that an individual's self-efficacy perception (e.g. how does an individual applies methods that are essential to cope with presented problems) affects his or her mindscape, behavioral preferences, and emotional responses. Perceived self-efficacy is an evaluation of the ability that requires applying specific kinds of performance. Self-efficacy beliefs affect people's pursued actions, consequences that they are expected from their efforts, how much they are affected by stress and depression, their life choices and their success [5], Self-efficacy is more important than actual abilities and skills in terms of explaining individual differences. In this context, self-efficacy concept comes into prominence about 
emotional skills. An individual who has high emotional self-efficacy is more tend to use his or her skill [25], Self-efficacy is extremely important in terms of coping with emotional experiences [39]. Bandura and his colleagues [8], asserted a regulatory emotional self-efficacy concept that heals negative emotional situation and expresses beliefs about experiencing positive emotions. Regulatory emotional self-efficacy and emotional self-efficacy aim to conceptualize a person's belief to his or her own emotional skills. Nevertheless, emotional self-efficacy is theoretically based on emotional intelligence model, it includes not only emotional regulation but also emotional skills such as understanding and perceiving emotions. Emotional self-efficacy is also different from skill- based emotional intelligence because this structure is not a person's own skill but his or her belief about this skill [25]. Emotional intelligence, which is defined as the ability to identify and express one's own emotions and the emotions of others, is correlated with emotional self-efficacy [36]. Mayer and Salovey [29], in emotional intelligence model, represented four emotional skills as follows: understanding one's own emotions and emotions of others, using emotions to ease thinking, understanding emotional complexity, and regulating one's own emotions and emotions of others. Emotional self-efficacy states individuals' beliefs about whether they are able to regulate their emotions or not [8]. Emotional self-efficacy has two components as follows: regulating negative consequences (an ability to overcome negative emotions such as anger, sadness, and guilt when experience a frustration), expressing positive effects that include experiencing positive emotions such as happiness and pride, and an ability to express those positive emotions. People who have low emotional self-efficacy have trouble in terms of coping with negative emotions when they experience distress, and they are more tend to get into depression [8]. Positive self-evaluation affects emotional self-efficacy [18]. Emotional self-efficacy positively affects subjective well- being and positive mood $[11 ; 12]$. Emotional self-efficacy has an important effect on person's social life. Indeed, emotional self-efficacy has both direct and indirect effects on empathy and life satisfaction [42].

\section{Method}

\subsection{Participants}

This research was conducted on 232 students in secondary school. Participants of the study $111(48 \%)$ were female and $121(52 \%)$ were male. The average age of the students is 12.8 .

\subsection{Measures}

The Emotional Self-Efficacy Scale(ESES) was comprised by Pool and Qualter. Results of analysis showed that the items loaded on four sub-dimension. Results of the Turkish version of the analysis indicated that the four- sub-dimension was well fit. Turkish version of the reliability coefficient of ESES as .92. Items of the ESES corrected total correlation coefficient were ranged between .38 and .59 .

Educational Stress Scale (ESS). - Educational Stress Scale was composed by Sun et al.[41] and it comprise of 16 items . Akın et al.[1] did Turkish version of reliability study of the ESS and consistency was .87. Results of the Turkish version of the analysis indicated that the five- sub-dimension was well fit. Item coefficients of ESS ranged from .40 to .60 .

\subsection{Procedure}

Participants are reached via convenience sampling. Convenience sampling is one of the nonprobability sampling methods, and the researcher selects participants who are easy to come by him/her. Students fill the scales anonymously. Data was analyzed by correlation and path analysis.

\section{Results}

Table 1. Descriptive statistics of Sub-dimensions

\begin{tabular}{|c|c|c|c|c|c|}
\hline Variables & Using & Identifying & Dealing & Perceiving & $\begin{array}{c}\text { Education } \\
\text { Stress }\end{array}$ \\
\hline Using & 1 & & & & \\
\hline Identifying & $.57^{* *}$ & 1 & & & \\
\hline Dealing & $.59^{* *}$ & $.56^{* *}$ & 1 & & \\
\hline Perceiving & $.56^{* *}$ & $.58^{* *}$ & $.63^{* *}$ & 1 & \\
\hline E. S. &.$-26^{* *}$ & $-.21^{*}$ & $-.18^{* *}$ & $-.17^{* *}$ & 1 \\
\hline Mean (SD) & $35(7.7)$ & $21(5.1)$ & $27(6.4)$ & $10(2.6)$ & $44(8.1)$ \\
\hline \multicolumn{7}{|c|}{$* *<.01$} \\
\hline
\end{tabular}

Table 1 show that there are significant negative correlations between emotional self-efficacy and educational stress. Subscales of the emotional self-efficacy; Using and managing your own emotions $(\mathrm{r}=-.26)$, Identifying and understanding one's own emotions $(\mathrm{r}=-.21)$, Dealing with emotions in others $(\mathrm{r}=-.18)$ and Perceiving emotion through facial expressions and body language $(\mathrm{r}=-.17)$ correlated negatively with emotional self-efficacy. Before the structural equation model (SEM) was conducted the assumptions had been considered. Multivariate normality tests that analyze whether or not the data set is convenient to normal distribution were carried out by LISREL and results represent normal distribution. Figure 1 shows the results of SEM findings. 


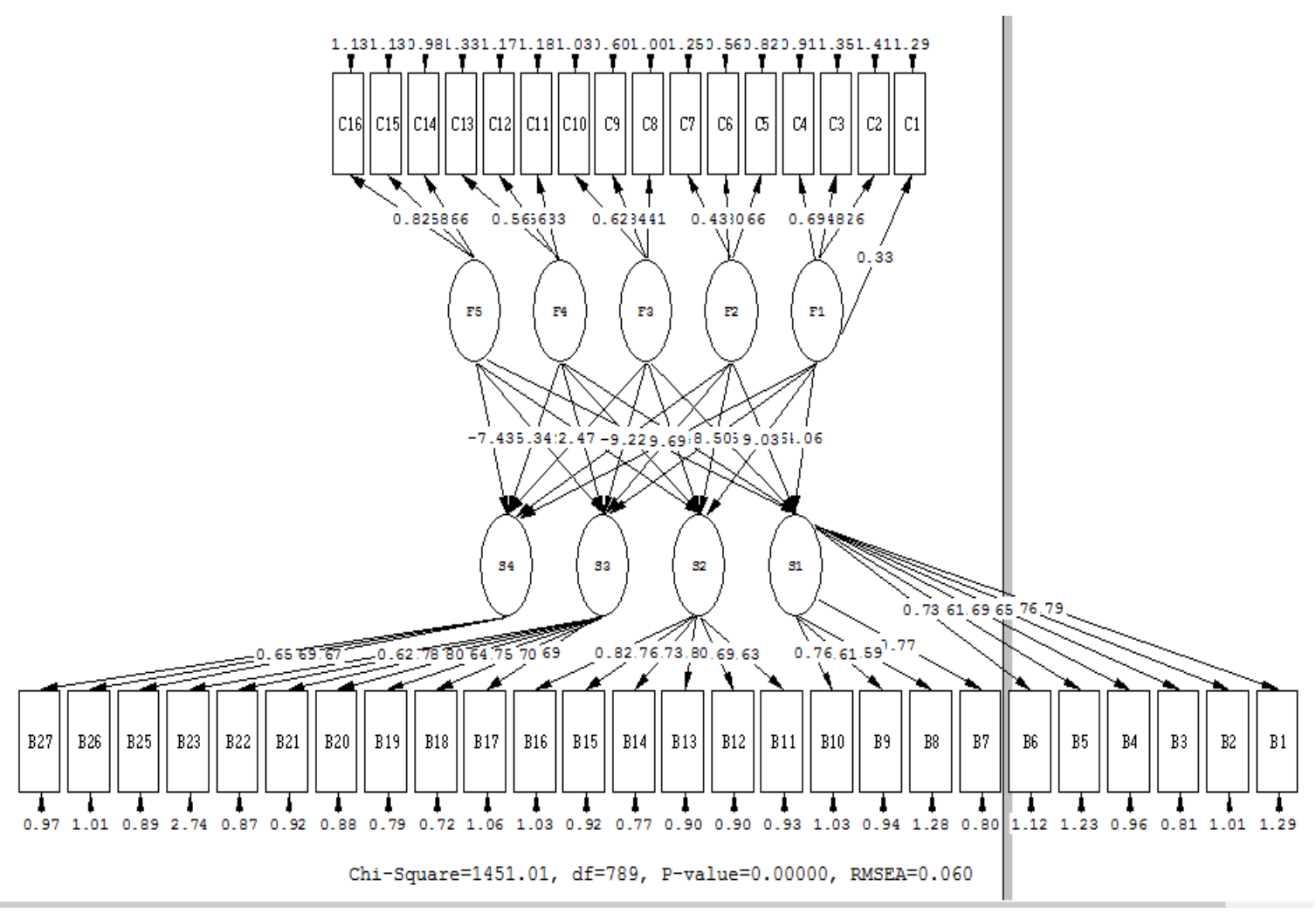

Figure 1. Structural Equation Model of Variables (F1,F2,F3,F4,F5=Sub-dimensions of Educational Stress S1,S2,S3,S4=Sub-dimensions of Emotional Self-Efficacy)

Fit index of SEM which were carried out in order to determine whether the Emotional self-efficacy predict educational stress or not, show good fit $\left(\chi^{2}=1451.01\right.$, df $=789, \mathrm{p}=0.00, \mathrm{NNFI}=.90, \mathrm{CFI}=.91, \mathrm{IFI}=.91, \mathrm{SRMR}=.072$, RMSEA $=0.060$ ). It can be seen that sub-dimensions of emotional self-efficacy have significant effects on educational stress.

\section{Discussion}

The present study indicates that high emotional self-efficacy decreases educational stress. These findings are in line with previous studies in the literature. According to Bandura's self-efficacy theory, person's own belief is a significant determiner of his or her performance. Perceived self-efficacy plays an important role in terms of processing emotional information; so that emotional self-efficacy is positively correlated with social relationships and academic performance. Moreover, emotional self-efficacy is effective in terms of coping with academic stress. Emotional self-efficacy decreases vulnerability against stress and depression, and strengthens endurance to negativity [6]. Stress lessens academic performance and cognitive skills [19]. Stress does not affect all students equally. Students who can cope with negative emotions and have high emotional self-efficacy experience less stress [22,32]. High emotional self-efficacy level leads to increase in academic achievement and decrease in behavioral problems [47, 3]. High emotional self-efficacy level contributes to life satisfaction, school achievement, positive thinking, one's belief about social competence and emotion regulation ability [40]. Studies show that emotional self-efficacy is positively associated with self- esteem, psychological well- being, and happiness [17,9], and contributes to conflict resolution and problem solving abilities[14]. Emotional self-efficacy enables substance use, victimization, depression and anxiety symptoms to decrease [30,26,32].According to Choi, Kluemper and Sauley [16] emotional self-efficacy is effective in terms of overcoming the stress and life satisfaction. Understanding and regulating one's own emotions subgroup of emotional self-efficacy is related to psychological consequences such as well- being and coping. Lazarus and Folkman [27], indicated that people who have an ability to regulate emotions are less tend to consider confrontations as threatening, and more tend to use effective coping strategies. In this sense people who can identify and regulate their emotions are successful in terms of coping with stress [16]. People with high emotional self-efficacy are more resistant to stressful life events [35].Abovementioned studies support the findings of the current study. Thus, emotional self-efficacy can seem as a supportive and positive variable for positive academic applications at school. Education stress is one of the significant problems in school life. Researchers point out that problem during childhood and adolescence period is associated with low emotional self-efficacy. Findings represent that increasing students' emotional self-efficacy levels may be effective in lessening 
educational stress. Emotional self-efficacy is considered as an aspect of emotional intelligence [4]. Emotional intelligence plays a role in the relationship between coping self-efficacy and academic stress [44]. Studies about emotional intelligence indicate that emotional intelligence has positive effects on academic achievement, health and well- being level [15,38 ]. Studies point out that it can be possible to increase one's emotional intelligence level and emotional self-efficacy level which is about one's own belief in terms of emotional functioning. Hence, it is possible to teach and improve emotional functioning [37]. Within this context, parents and teachers should do something to increase students' emotional self-efficacy levels, and create opportunity for students to support their development. In the literature, some studies indicate that perceived parental attitudes affect emotional self-efficacy and anxiety [34]. In this regard, supportive and democratic parental attitudes instead of rejectionist one, are important in terms of solving adolescent problems. Empathy is another concept which affects emotional self-efficacy and life satisfaction [42]. Thus, it is important to do group guidance, class guidance, and family education activities that aim to increase students' empathy skills. Emotional self-efficacy is related to positive psychology concepts such as psychological well- being, and gratitude, so that positive psychology applications may be performed at schools. Future studies may examine the relationship between emotional self-efficacy and variables such as peer victimization, anger problems, conflict situations that seems important problems of adolescence period. The present study was conducted with secondary school students; prospective studies may support these findings with different samples.

\section{REFERENCES}

[1] Akın, A., Gediksiz, E., Arslan, S., \& Akın, Ü. (2012). The validity and reliability of the Turkish version of educational stress scale for adolescents (ESSA).International Conferences on New Horizons in Education, 2-8 Haziran, Czech Republic/Prague.

[2] Ang, R. P., \& Huan, V. S. (2006). Relationship between academic stress and suicidal ideation: Testing for depression as a mediator using multiple regression. Child Psychiatry \& Human Development, 37, 133-143.

[3] Armum,P. \& Chellappan, K. (2015). Social and emotional self-efficacy of adolescents: measured and analysed interdependencies within and across academic achievement level. International Journal of Adolescence and Youth, 21 (3), 279-288.

[4] Bandura, A. (1986). Social foundations of thought and action: A social cognitive theory. Englewood Cliffs, NJ: Prentice Hall.

[5] Bandura, A. (1997). Self-efficacy: The exercise of control. New York: W.H. Freeman and Company.

[6] Bandura, A. (2001). Social cognitive theory: An agentic perspective. Annual Review of Psychology, 52, 1-26.
[7] Bandura, A. (2006). Guide for constructing self-efficacy. In F. Pajares \& T. Urdan (Eds.), Self-efficacy beliefs of adolescents (pp. 307-337). Greenwich, CT: Information Age Publishing.

[8] Bandura, A., Caprara, G. V., Barbaranelli, C., Gerbino, M., \& Pastorelli, C. (2003). Role of affective self-regulatory efficacy in diverse spheres of psychosocial functioning. Child Development, 74, 769-782.

[9] Beri, N. \& Jain, M. (2016). Personal growth initiative among undergraduate students: Influence of emotional self-efficacy and general well-being. Rupkatha Journal on Interdisciplinary Studies in Humanities Special Issue, 8 (2).

[10] Bhansali, R. \& Trivedi, K. (2008). Is academic anxiety gender specific: A comparative study. Journal Social Science., 17(1), $1-3$.

[11] Brackett, M. A., \& Mayer, J. D. (2003). Convergent, discriminant, and incremental validity of competing measures of emotional intelligence. Personality and Social Psychology Bulletin, 29, 11471158

[12] Brackett, M. A., Mayer, J. D., \& Warner, R. M. (2004). Emotional intelligence and its relation to everyday behavior. Personality and Individual Differences, 36, 1387-1402.

[13] Byrne,D.G, Davenport, S.C., \& Mazanov, J. (2007). Profiles of adolescent stress: The development of the adolescent stress questionnaire. Journal of Adolescence, 30, 393-416.

[14] Caldas, S.V., Broaddus, E.T. \& Winch, P.J. (2016). Measuring conflict management, emotional self-efficacy, and problem solving confidence in an evaluation of outdoor programs for inner-city youth in Baltimore, Maryland. Evaluation and Program Planning 57, 64-71.

[15] Chauhan, S. (2011). A study of relationship between emotional intelligence and adjustment among college going students. International Journal of Education \& Allied Sciences, $3,79-82$.

[16] Choi, S., Kluemper, D. H., \& Sauley, K. S. (2013). Assessing emotional self-efficacy: Evaluating validity and dimensionality with cross-cultural samples. Applied Psychology, 62(1), 197-123.

[17] Dogan, T., Totan, T. \& Sapmaz, F. (2013). The Role of Self-Esteem, Psychological well-Being, Emotional Self-efficacy, and Affect Balance on Happiness: A Path Model. European Scientific Journal, 9(20).

[18] Dou, K. Wang, Y.J., L1, J.B. \& L1u, Y.Z. (2016). Core self-evaluation, regulatory emotional self-efficacy, and depressive symptoms: testing two mediation models. Social Behavior and Personality, 44(3), 391-400.

[19] Eysenck, M. W., Derakshan, N., Santos, R., \& Calvo, M. G. (2007). Anxiety and cognitive performance: Attentional control theory. Emotion, 7(2), 336-353.

[20] Hess, R.S. \& Copeland, E.P. (2006). Stress. In: G. G. Bear \& K. M. Minke (Eds.), Children's needs III: Development, prevention, and intervention (pp. 255- 265). Washington, DC: National Association of School Psychologists.

[21] Hudd,S.S., Dumlao, J., Erdmann-Sager,D., Murray,D., Phan,E., \& Soukas,N. (2000). Stress at college: effects on health habits, health status and self-esteem. College Student Journal, 34(2), 217. 
[22] Galla, B.M. \& Wood, J.J. (2012). Emotional self-efficacy moderates anxiety-related impairments in math performance in elementary school-age youth. Personality and Individual Differences, 52, 118-122.

[23] Jones, R. (1993). Gender-specific differences in the perceived antecedents of academic stress. Psychol. Rep. 72, 739-743.

[24] Jones,R.W. \& Hattie, J.A. (1991). Academic stress amongst adolescents: An examination by ethnicity, grade and sex. Paper presented at the Annual Conference of the New England Educational Research Organization, April 24-26, in Portsmouth.

[25] Kirk, B. A., Schutte, N. S., \& Hine, D. (2008). Development and preliminary validation of an emotional self-efficacy scale. Personality and Individual Differences, 45(5), 432-436.

[26] Kokkinos, C. M., \& Kipritsi, E. (2012). The relationship between bullying, victimization, trait emotional intelligence, self-efficacy and empathy among preadolescents. Social Psychology of Education, 15(1), 41-58.

[27] Lazarus, R. \& Folkman, S. (1984). Stress, appraisal, and coping. New York: Springer.

[28] Li, J., Feng, X., Mei, S., \& Yao, D. (2007). Investigation of Study Pressure Effects on Mental Health of Junior High School Students in Changchun. Medicine and Society, 20(2), 56-57.

[29] Mayer, J.D., \& Salovey, P. (1997). What is emotional intelligence? In P. Salovey \& D.J. Sluyter (Eds.), Emotional development and emotional intelligence (pp. 3-31). New York: Basic Books.

[30] McKay, M. T., Sumnall, H. R., Cole, J. C., \& Percy, A. (2012). Self-esteem and self-efficacy: associations with alcohol consumption in a sample of adolescents in Northern Ireland. Drugs: Education, Prevention and Policy, 19(1), 72-80.

[31] Misra, R., \& Castillo, L. G. (2004). Academic stress among college students: Comparison of American and international students. International Journal of Stress Management, 11, $132-148$.

[32] Muris, P. (2001). A brief questionnaire for measuring self-efficacy in youths. Journal of Psychopathology and Behavioral Assessment, 23(3), 145-149.

[33] Nakalema, G., \& Ssenyonga, J. (2014). Academic stress: Its causes and results at a Ugandan university. African Journal of Teacher Education, 3, 1-21.

[34] Niditch, L. A., \& Varela, R. E. (2012, February). Perceptions of parenting, emotional self-efficacy, and anxiety in youth: test of a mediational model. In Child \& Youth Care Forum (Vol. 41, No. 1, pp. 21-35). Springer US.

[35] Palesh, O. G., Shaffer, T., Larson, J., Edsall, S., Chen, X. H., Koopman, C., ... \& Parsons, R. (2006). Emotional self efficacy, stressful life events, and satisfaction with social support in relation to mood disturbance among women living with breast cancer in rural communities. The breast journal, 12(2), 123-129.
[36] Petrides, K. V., \& Furnham, A. (2003). Trait emotional intelligence: Behavioral validation in two studies of emotion recognition and reactivity to mood induction. European Journal of Personality, 17, 39-57.

[37] Pool, D. L. \& Qualter, P. (2012). Improving emotional intelligence and emotional self-efficacy through a teaching intervention for university students. Learning and Individual Differences, 22, 306-312.

[38] Pope, D., Roper, C., \& Qualter, P. (2012). The influence of emotional intelligence on academic progress and achievement in UK University students. Assessment and Evaluation in Higher Education, 37, 907-918.

[39] Saarni, C. (1999). The development of emotional competence. New York: Guilford Press.

[40] Schunk, D. H. (2005). Commentary on self-regulation in school contexts. Learning and Instruction, 15(2), 173-177.

[41] Sun, J., Dunne,M.P., Hou,X., \& Xu,A. (2011). Educational stress scale for adolescents: Development, validity, and reliability with Chinese students. Journal of Psychoeducational Assessment, 29(6), 534-546.

[42] Totan, T. \& Şahin, R. (2015). The stepwise effect of emotional self-efficacy processes and emotional empathy on young people's satisfaction with life. European Scientific Journal, 11 (14), 442-456.

[43] Verma, S. \& Gupta, J. (1990). Some aspects of high academic stress and symptoms. Journal of Personality and Clinical Studies, 6, 7-12.

[44] Watson,J.C. \& Watson, A.A. (2016). Coping self-efficacy and academic stress among Hispanic first-year college students: The moderating role of emotional intelligence. Journal of College Counseling, 19.

[45] Weidner, G., Kohlmann, C. W., Dotzauer, E., \& Bums, L. R. (1996). The effects of academic stress on health behaviors in young adults. Anxiety, Stress, \& Coping: An International Journal, 9, 123-133.

[46] Wenz-Gross, M., \& Siperstein, G. N. (1997). Importance of social support in the adjustment of children with learning problems. Exceptional Children, 63, 183-193.

[47] Wigelsworth,M., Qualter, P. \& Humphrey, N. (2016). Emotional self-efficacy, conduct problems, and academic attainment: Developmental cascade effects in early adolescence. European Journal of Developmental Psychology.

[48] Xie, L.N. (2007). Study on Learning Stress, Social Support and their relationship among Senior High School Students: An Investigation of Two Senior High Schools in Hennan Province. Unpublished Master Thesis, Huadong Normal University.

[49] Zhang,L., Qin,S., Yaoa,Z., Zhang,K. \& Wu,J. (2016). Long-term academic stress enhances early processing of facial expressions. International Journal of Psychophysiology, 109, $138-146$.

[50] Zhao, L.X., \& Yuan, L. (2006). Investigation on the current status of academic stress among secondary school students. Journal of Tianjin Academy of Educational Science(2),18-21,67. 